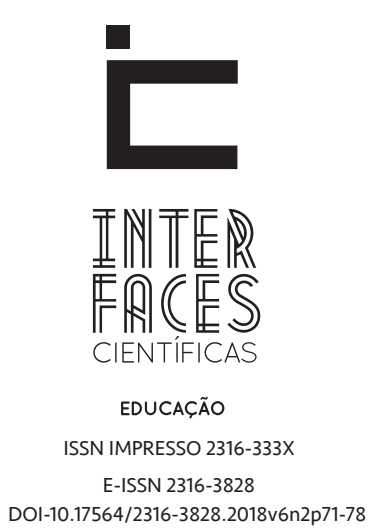

\title{
OS PROCESSOS IDENTITÁRIOS DO PROFESSOR E AS RELAÇÕES COM AS SUAS PRÁTICAS EDUCATIVAS NO ENSINO SUPERIOR: ALGUMAS REFLEXÕES
}

\author{
TEACHER IDENTITY PROCESSES AND RELATIONSHIPS WITH THEIR EDUCATIONAL PRACTICES IN HIGHER EDUCATION: \\ SOME REFLECTIONS.
}
LOS PROCESOS DE IDENTIDAD DEL MAESTRO Y RELACIONES CON SU PRÁCTICA EDUCATIVA EN LA EDUCACIÓN SUPERIOR: ALGUNAS REFLEXIONES.

\section{RESUMO}

O presente artigo tem a intenção de apresentar uma breve reflexão resultante da análise de alguns trabalhos publicados em periódicos nacionais e internacionais referentes aos processos identitários do professor procurando investigar como as publicações sobre identidade docente tem articulado estes processos às práticas e a formação docente. Para a pesquisa e seleção dos textos foram utilizadas as seguintes palavras-chaves: Processos Identitários, Práticas docentes, trajetórias docentes e formação de professores. Foi observado que todos os trabalhos selecionados relacionam os proces- sos identitários às práticas profissionais e à formação docente de forma direta e indireta. Porém não foram encontradas investigações sobre as relações dos processos identitários dos docentes com a percepção da relação ensino-aprendizagem e sobre a formação prospectiva do professor.

\section{PALAVRAS-CHAVE}

Processos Identitários. Práticas docentes. formação docente. 


\section{ABSTRACT}

This article intends to present a brief reflection resulting from the analysis of some papers published in national and international periodicals related to the identity processes of the teacher trying to investigate how the publications on teacher identity have articulated these processes to the practices and the teacher formation. For the research and selection of texts, the following keywords were used: Identity Processes, Teaching practices, teaching trajectories and teacher training. It was observed that all selected papers relate the processes of identity to professional practi-

\section{RESUMEN}

Este artículo se destina a proporcionar una breve reflexión que resulta del análisis de algunos trabajos publicados en revistas nacionales e internacionales relacionadas con los procesos de identidad maestro que buscan investigar cómo las publicaciones sobre la identidad de la enseñanza ha articulado estos procesos y prácticas de la formación del profesorado. Para la búsqueda y selección de textos se utilizaron las siguientes palabras clave: procesos de identidad, las prácticas de los maestros, profesores y carreras de formación docente. Se observó que todas las obras seleccionadas se ces and teacher training in a direct and indirect way. However, no research was found on the relations of the teachers' identity processes with the perception of the teaching-learning relationship and on the prospective teacher formation

\section{KEYWORDS}

Identity Processes. Teaching practices. teacher training.

relacionan los procesos de identidad a la práctica profesional y formación del profesorado, directa e indirectamente. Pero no hubo investigaciones sobre las relaciones de los procesos de identidad de los profesores con la percepción de la relación enseñanza-aprendizaje y en la formación prospectiva de profesores.

\section{PALABRAS CLAVE}

Procesos de identidad. Prácticas de enseñanza. Formación del profesorado. 
Pensar em processos identitários acarreta pensar em uma série de fatores que influenciam, transformam e conduzem à formação da identidade do homem. Não, não temos uma identidade rígida, estática, imutável. O contrário disso é o que ocorre em nossas vidas. 0 tempo, todos os acontecimentos diários, a religião, as relações sociais que estabelecemos, as expectativas que criamos, as pressões sociais e culturais que sofremos, a condição econômica em que nos encontramos e muitos outros fatores interferem nas transformações dos nossos processos identitários. Não obstante, a nossa escolha profissional e o exercício dessa profissão também são agentes transformadores e formadores da nossa identidade profissional.

Nessa perspectiva a identidade do docente está sujeita aos diversos contextos em que a sua atuação profissional está inserida, dentre esses a sua prática profissional e a sua formação docente.

O Presente trabalho tem como objetivo investigar como estão sendo desenvolvidos os estudos acerca dos processos identitários do docente e como eles tem articulado estes processos às práticas e a formação docente.

Para isso foram levantadas algumas questões:

- Como os processos identitários dos docentes são estudados na literatura atual?

- Há estudos que relacionem os processos identitários às práticas docentes e a formação profissional?

- Como a literatura relaciona os processos identitários às práticas docentes e a formação profissional?

- Quais lacunas podem ser visualizadas a partir da literatura investigada?

Este artigo corresponde a uma revisão de literatura, foram pesquisados alguns textos voltados para os seguintes temas ou palavras chaves: Processos Identitários, Práticas docentes, Trajetórias docentes e Formação de professores. Além desses trabalhos, foram também utilizados alguns artigos publicados em revistas indexadas da área sobre as temáticas aqui descritas.

Partimos aqui de uma perspectiva de identidade fluida em contínuo processo de construção e reconstrução. Laurenti e Barros (2000) entendem que a identidade não pode ser considerada inata ao ser humano e, sim, histórico-social, ou seja, uma singularidade edificada, histórica e socialmente, nas relações do indivíduo com seus semelhantes.

Os valores e os significados cognitivos e emocionais gerados no indivíduo pelos grupos e categorias sociais de que este faz parte são fundamentais para a formação de parte do seu autoconceito e, conseqüentemente, da sua identidade social (TAJFEL, 1978). Para Tajfel (1978) a categorização social em um determinado grupo tem a função de auxiliar o indivíduo a estruturar a compreensão causal do meio social e, por meio dessa compreensão, elaborar suas ações. Com o professor não seria diferente, ao contrário. A sua relação com o aluno, a construção social desta interação interfere no seu processo identitário e, consequentemente, na sua prática profissional.

Percebe-se, diante do exposto, que as estruturas individuais e sociais modificam-se, de maneira concomitante, de forma dinâmica, entrelaçada, de modo que a singularidade específica de cada indivíduo, ou seja, seu caráter individual é moldado de acordo com as relações humanas e por meio delas (ELIAS, 1987). Dessa forma, Elias (1987) explica essa inter-relação entre indivíduo e sociedade exemplificando-a por meio da metáfora da rede:

\footnotetext{
Nessa rede, muitos fios isolados ligam-se uns aos outros. No entanto, nem a totalidade da rede nem a forma assumida por cada um de seus fios podem ser compreendidas em termos de um único fio, ou mesmo de todos eles, isoladamente considerados; a rede só é compreensível em termos da maneira como eles se ligam, de sua relação recíproca. Essa ligação origina um sistema de tensões para o qual cada fio isolado concorre, cada um de maneira um pouco diferente, conforme seu lugar e função na totalidade da rede. A forma do fio individual se modifica quando se alteram a tensão e a estrutura da rede inteira. No entanto essa
} 
rede nada é além de uma ligação de fios individuais; e, no interior do todo, cada fio continua a constituir uma unidade em si; tem uma posição e uma forma singulares dentro dela. (p.35)

A metáfora utilizada por Elias (1987) para explicar a inter-relação indivíduo e sociedade demonstra a complexidade e a dinâmica dessa relação, em que a unidade indivíduo-sociedade depende da diversidade de funções, da reciprocidade existente entre eles. Na sociedade, como no exemplo da rede, o indivíduo não pode ser considerado de forma isolada, mas como parte do contexto das relações. A alteração de um indivíduo em particular repercute no contexto social e vice-versa.

Berger e Luckman (2004) afirmam que a identidade individual é, antes de tudo, social e que as estruturas da consciência individual são formadas pelas estruturas sociais. Isso ocorre porque as instituições sociais e seus esquemas são internalizados na consciência do indivíduo, substituindo seus instintos e conduzindo suas atitudes. Essa internalização, segundo esses autores, se dá em

Processos de camadas múltiplas; em primeiro lugar, na 'socialização primária', em que se coloca a pedra fundamental da construção da identidade pessoal; depois na 'socialização secundária', que introduz o indivíduo nos papéis da realidade social, sobretudo no mundo do trabalho (BERGER; LUCKMAN, p. 55-56).

A 'socialização primária' refere-se ao momento em que o indivíduo compreende e incorpora em sua singularidade, como seu o mundo no qual está inserido, tornando-se assim membro da sociedade e a 'socialização secundária' é a compreensão dos submundos institucionais ou baseados em instituições do mundo já incorporadas (BERGER; LUCKMANN, 1994).

Conforme vimos, a identidade tem uma relação dialética com a sociedade, já que é formada pelos processos sociais determinados pela estrutura social e, quando cristalizada, é nas relações sociais que a identidade encontra a sua manutenção, modificação e remodelação (BERGER; LUCKMANN, 1994).
A identidade está relacionada a constituição do sujeito perante o mundo e as circunstâncias em que ele se encontra inserido. Para que seja compreendida em toda a sua complexidade é necessário que se considere os aspectos ontológicos, culturais e sociais que atuam na constituição do indivíduo enquanto sujeito, isto é, na sua identidade (RODRIGUES; MOSQUERA; STOBAUS, 2016).

Dadas as devidas teorizações e definições que embasam o objeto de estudo deste trabalho, partiremos para a análise de alguns trabalhos literários publicados relativos ao tema aqui proposto.

Inicialmente conversaremos com o trabalho de Powaczuk e Bolzan (2011), que refletem sobre o início da docência universitária. As autoras baseiam suas pesquisas na premissa de que os professores que exercem a docência nas Instituições de Ensino Superior, sem experiência e preparo para atuar na graduação passam por "um complexo processo de elaboração entre o já vivido e a criação de novas e distintas configurações do seu agir, combinadas às exigências e necessidades que se apresentam no contexto da profissão docente" (POWACZUK; BOLZAN, 2011, p. 1).

As autoras em questão não tratam diretamente da identidade profissional do docente, mas tratam da produção de subjetividade, da influência da trajetória profissional na vida pessoal.

Isso significa dizer que as vivencias pelas quais os professores passam ao longo de seu percurso formativo podem incidir sobre o fazer-se docente de modo distinto, tendo em vista as possibilidades de interpretação e de [re]significação que este traz consigo nos diferentes momentos de sua trajetória. (POWACZUK; BOLZAN, 2011, p. 1).

Apesar das autoras não tratarem diretamente da identidade de forma explícita, indiretamente percebe-se no texto a influência das trajetórias e práticas docentes na pessoalidade do docente e na sua vivência profissional. Esses achados são de fundamental importância para a investigação dos processos identitários do docente.

Um estudo bastante interessante sobre a identidade profissional do docente foi realizado por Franco e 
Gentil (2007), no qual os processos identitários do docente eram relacionados a inúmeras variáveis como o próprio contexto da instituição, as relações estabelecidas nesses contextos etc.

Segundo Franco e Gentil (2007), para que possamos compreender a identidade do professor do ensino superior é necessário que consideremos as interligações entre diversos fatores que permeiam a sua formação identitária. Dentre esses fatores as autoras citam os laços ou vínculos institucionais que demandam a inserção destes em uma pluralidade de grupos e, consequentemente, uma série de papéis a serem exercidos pelos docentes que se entrecruzam.

Nesse sentido, as identidades docentes vão se construindo em uma relação entre

[...] trabalho, formação, vida pessoal, história, políticas públicas e o lugar de onde cada professor/grupo re-significa a identidade a cada tempo, espaço e projeto coletivo. Assim, é preciso falar de identidades sem esquecer que determinar a identidade coletiva e profissional do professor pode ser uma das especificidades da profissão na identificação entre profissionais. (FRANCO; GENTIL, 2007, p. 43).

Observa-se que, tanto os vínculos institucionais quanto as relações sociais do professor são elementos constitutivos não só da sua identidade, mas de suas práticas e da sua formação.

Nesse processo, as autoras destacam algumas possibilidades de questões que consideram relevantes, na época atual, como: a relação de trabalho, as políticas públicas e as relações e interpretações que os professores estabelecem e elaboram a partir destas, o processo de formação e as elaborações de significados que surgem a partir desses processos, as diversas práticas profissionais, o espaço de atuação profissional e, finalmente, os objetivos profissionais (FRANCO; GENTIL, 2007).

As autoras articulam de forma explícita as práticas educativas aos processos identitários, afirmando que a identidade do professor,

[...] se dá nas interligações, no entrecruzar de redes e nos espaços de interlocução nos quais a trajetória do indivíduo, o campo disciplinar formativo, as áreas de conhecimento, o trabalho profissional e suas práticas e os laços institucionais têm papel basilar. (FRANCO; GENTIL, 2007, p. 8).

Apesar de se considerar a importância das práticas e da formação docente nos processos identitários do professor, as autoras dão maior ênfase à formação profissional, as demandas e relações estabelecidas institucional e socialmente.

0 contexto em que o docente está inserido influencia sua identidade docente, porém se cristaliza de maneira particular em cada um, decorrendo das escolhas relacionadas à formação profissional e pessoal de cada professor (SOARES, 2014).

Figueiredo (2010, p.163), ao investigar a construção da identidade na formação docente em Educação Física, conclui que esse processo de construção de identidades dos professores se "constitui e é constituído por uma articulação de identidade "para si”, de identidade atribuída pelo outro", de inter-relações entre o trabalho e a formação e, por fim, de relações pessoais-profissionais, além de diversas outras dimensões não mencionadas aqui.

Segundo a autora, não basta ressaltar a instabilidade da identidade, mas deve ser levada em consideração que a formação identitária é contínua e está o tempo todo conectada aos eventos externos e as suas modificações, se adaptando a eles "como quando se pensa nas relações que o professor precisa (re)construir com os saberes especializados da atividade profissional, no sentido de ter que passar a gerir novas relações" (FIGUEIREDO, 2010, p. 163).

A (re)construção identitária também pode ser demonstrada a partir da pesquisa de Siqueira (2006), o qual observou que a identidade dos docentes das Instituições de Ensino Superior (IES) particulares de Brasília-DF é constituída a partir da interseção das relações sociais, especialmente o reconhecimento social. Porém, foi verificado que alguns elementos como o desencantamento e o sofrimento são bastante comuns entre esses docentes, pois lidam com contradições próprias do modelo de gestão que funciona de 
acordo com as exigências de mercado e que se refletem na atuação desses professores e, consequentemente, na (des)construção de suas identidades. Além disso, fatores como medo da demissão, do fracasso profissional, aliados à impossibilidade ou restrições de acesso a qualificações voltadas a construção de sua carreira (SIQUEIRA, 2006).

Diante da pluralidade do mundo atual, o homem tem a sua disposição uma infinidade de ofertas, de caminhos e de escolhas a serem feitas. Praticamente todas as atitudes humanas envolvem uma decisão. Essa multiplicidade de ofertas se encontra nos mais diversos campos da vida dos homens, atingindo desde os costumes mais corriqueiros até os campos mais complexos, como a profissão, a sexualidade, a religião, entre outros. Nesse contexto, Berger e Luckmann (2004, p. 73) afirmam que o pluralismo moderno "tende a desestabilizar as auto-evidências das ordens de sentido e de valor que orientam as ações e sustentam a identidade".

Segundo Moraes (2009), a identidade do professor encontra-se sob a influência de múltiplos fatores, advindos das diversas transformações, cada vez mais rápidas, a que as próprias instituições de ensino e a sociedade em geral também sofrem. Essas mudanças ocorrem em todas as esferas da atividade humana, modificando papéis e valores tradicionalmente arraigados, gerando novas exigências aos docentes (MORAES, 2009).

Neste sentido considera-se que o trabalho é um meio importante e imprescindível para o desenvolvimento do indivíduo, promovendo neste a aquisição de status social, da identidade e da sensação de pertencimento a um grupo social. 0 homem neste ambiente constitui e mantem relações sociais, trocas de experiências e afetivas. 0 sofrimento no âmbito laboral pode acarretar prejuízos e transformações na identidade e no desempenho do sujeito (SEABRA; SILVA; DUTRA, 2015).

Morgado (2011) ao estudar a identidade docente, relaciona as práticas curriculares destes profissionais ao processo identitário desde as palavras chaves. Para ele, a identidade do docente se manifesta e se concretiza em suas atuações e em suas práticas. Essas práticas tendem a responder uma demanda específica, determinada pela disciplina, pelo perfil do aluno e pela instituição. Tradi- cionalmente a prática profissional é concebida a partir das competências e habilidades profissionais que, por sua vez, são vistas como consequentes de um determinado saber. Porém para o professor a sua prática profissional não se limita a um saber restrito a conhecimentos científicos determinados (MORGADO, 2011).

Contudo, Morgado (2011) ressalta que o saber profissional do docente não pode se limitar ao domínio dos conteúdos científicos curriculares ou das ciências da educação. Esse saber e, consequentemente, sua prática estão, de fato, relacionados à circunstância em que ela é manifestada, ao contexto social em que ela penetra e atua, ou nas palavras de Morgado (2011, p. 799) a prática educativa leva o professor a "apropriar-se dos verdadeiros sentidos que subjazem aos processos de aprendizagem e lidar, de forma profícua, com as diferenças que caracterizamos alunos e os contextos com que trabalha quotidianamente".

Isaia, Maciel e Bolzan (2010, p. 1) ao investigarem sobre os ciclos de vida profissional dos professores de ensino superior em IES públicas e privadas, compreenderam a existência de "movimentos construtivos da docência" que articulam o pessoal, o institucional e o profissional e como esses aspectos se transformam no decorrer da trajetória docente. As autoras ressaltam que estão imbricados a esses movimentos construtivos as singularidades e as formas de vivenciar e interpretar as situações de cada docente.

Pereira (2007) estudou o percurso histórico de quatro professores, procurando compreender, nesta trajetória, a individualidade e as influências vivenciadas, envolvendo suas crenças e escolhas. 0 autor direcionou sua atenção para o processo de construção da identidade dos sujeitos, objetivando compreender os fatores que os levaram a fazer suas escolhas profissionais, enfatizando que estas escolhas são refletidas diretamente nas atuações profissionais destes docentes. 0 autor tem como uma das conclusões da sua tese que o processo identitário, dos professores envolvidos, é contínuo, flexível e dinâmico interferindo de forma direta nas suas ações pedagógicas.

Rodrigues (2016), ao analisar o impacto da gestão no processo identitário de um docente em uma insti- 
tuição pública de ensino superior, verificou que a prática da gestão provocou mudanças concretas na identidade do docente, tornando-o mais apto ao exercício de condução do cargo de coordenação, levando-a a criar estratégias pessoais para lidar com as pressões institucionais. Para isto, a autora afirmou que o docente em questão, travava, para este fim, lutas pessoais de autoconhecimento e autocontrole e considerou que, de uma forma geral, observa-se que, direta ou indiretamente, sempre há uma articulação entre os processos identitários do docente, as demandas institucionais e suas práticas profissionais.

De uma forma geral, observa-se que, direta ou indiretamente, sempre há uma articulação entre os processos identitários do docente, sua formação e suas práticas profissionais. Porém, este é um estudo inicial e, muita literatura, ainda falta ser levantada e investigada para que se possa chegar a uma conclusão mais consistente.

Até o ponto aqui investigado, percebe-se que uma das possíveis lacunas visualizadas é referente a percepção da relação ensino-aprendizagem por parte do docente. Procurar compreender como o professor percebe essa relação e como essa percepção se inter-relaciona com o seu processo identitário e nas suas práticas pedagógicas seria, talvez, mais um elemento a ser considerado para a construção da identidade docente. Uma outra lacuna seria relacionada a influência desse processo identitário na formação prospectiva do professor. Questões voltadas para o entendimento de como a formação alcançada, as práticas elaboradas e a identidade construída influenciam a formação, as opções, expectativas e práticas futuras do professor também se tornam relevantes.

\section{REFERÊNCIAS}

BERGER, P.;e LUCKMANN, T. A construção social da realidade. Petrópolis-RJ: Vozes, 1994.

BERGER, P.; LUCKMANN, T. Modernidade, pluralismo e crise de sentido: a orientação do homem moderno. Petrópolis -RJ:Vozes, 2004.
ELIAS, N. A sociedade dos indivíduos. Rio de Janeiro: Zahar, 1987.

FIGUEIREDO, Z.C.C. Experiências profissionais, identidades e formação docente em educação física. Rev. Port. de Educação, Braga, v.23, n.2, 2010.

FRANCO, M.E.D.P.; GENTIL, Heloisa Salles. Identidade do professor de ensino superior: questões no entrecruzar de caminhos. In: FRANCO, M.E.D.P.; KRAHE E. D. (Org.). Pedagogia universitária e áreas de conhecimento. Porto Alegre: Série RIES/PRONEX EdiPucrs,v.1, 2007. p.39-58.

HALL, S. A identidade cultural na pós-modernidade. Rio de Janeiro: DP \&A. 2003.

ISAIA, S.M.A; MACIEL, A.M.R; BOLZAN, D.P.V. Educação superior: a entrada na docência universitária. 33a Reunião Anual da ANPED, Anais..., Caxambu, MG, 2010.

LAURENTI, C; BARROS, M.N.F. Identidade: questões conceituais e contextuais. Revista de Psicologia Social e Institucional, Londrina, v.2, n.1, jun. 2000.

MORAES, M.S. Memória e reflexão: A biografia como metodologia de investigação e Instrumento de (auto) formação de professores de arte. $18^{\circ}$ Encontro da Associação Nacional de Pesquisadores em Artes Plásticas, Transversalidades nas Artes Visuais, Anais.., Salvador-BA, 2009.

MORGADO, J.C. Identidade e profissionalidade docente: sentidos e (im)possibilidades. Ensaio: aval. pol. públ. Educ., Rio de Janeiro, v.19, n.73, p.793-812, out-dez. 2011.

PEREIRA, G.A. No fio da história: uma análise da (re) construção identitária dos professores - entrecruzando tempos, memórias e espaços. 2007. Tese (Doutorado) - Programa de Pós-graduação em Educação da 
Pontifícia Universidade Católica do Rio Grande do Sul (PUCRS), Porto Alegre, 2007.

POWACZUK, A.C.H; BOLZAN, D.P.V. Atividades de produção da docência: a professoralidade universitária. $34^{\circ}$ Reunião Anual da ANPED, Anais..., Natal, RN, 2011.

RODRIGUES, A.B.G.C. Impactos da prática da gestão na identidade de um docente do ensino superior. $9^{\circ}$ Encontro Internacional de Formação de Professores (ENFOPE). Anais..., Aracaju-SE, maio 2016. p.1-12.

RODRIGUES, A.B.G.C; STOBÄUS, C.D; MOSQUERA, J.J Identity as Study Object of Positive. Psychology. Creative Education, v.7, n.8, p.1119-1125, 2016. doi: 10.4236/ce.2016.78116.

SEABRA, M.M.A.; SILVA; DUTRA, F.C.M. Intensificação do trabalho e percepção da saúde em docentes de uma Universidade pública Brasileira. Cienc Trab., Santiago, v.17, n.54, p.212-218, dez. 2015.

\section{SIQUEIRA, T.C.A. 0 trabalho docente nas instituições} de ensino superior privado em Brasília. 2006. Tese (Doutorado) - Programa de Pós-graduação em Sociologia da Universidade de Brasília, UNB, Brasília, 2006.

SOARES, M. A formação da identidade docente no ensino superior. Cadernos de Educação, v.13, n.26, p.120-132, jan-jun. 2014.

TAJFEL, H. Social categorization, social identity and social comparison. In: TAJFEL, H (Ed.). Differentiation between social groups: studies in the social psychology of intergoup relations. London: Academic Press, 1978. p.61-76. 